\title{
PENATAAN KAWASAN SEKITAR STASIUN SUDIMARA DENGAN KONSEP TOD (TRANSIT ORIENTED DEVELOPMENT)
}

\author{
Bisma Wikanthyasa $\operatorname{Irawan}^{11}$, Liong Ju Tjung ${ }^{2)}$, Sylvie Wirawati ${ }^{3)}$ \\ 1)Program Studi S1 PWK, Fakultas Teknik, Universitas Tarumanagara, wikanthyasa.bisma@gmail.com \\ 2)Program Studi S1 PWK, Fakultas Teknik, Universitas Tarumanagara, liongjutjung@gmail.com \\ 3) Program Studi S1 PWK, Fakultas Teknik, Universitas Tarumanagara, sylvie.wirawati@gmail.com
}

Masuk: 10-08-2020, revisi: 08-09-2020, diterima untuk diterbitkan: 25-09-2020

\begin{abstract}
Abstrak
Kota Tangerang Selatan menjadi salah satu kota pilihan hunian bagi para komuter. Walikota Tangerang Selatan mengatakan bahwa lebih dari 50\% warganya bekerja di DKI Jakarta. Transportasi yang digunakan para komuter untuk beraktivitas sehari-hari adalah KRL Commuter Line. Stasiun Sudimara yang terletak di Kota Tangerang Selatan merupakan stasiun tertinggi kedua pada sistem KRL Commuter Line di Jalur Rangkasbitung dalam perolehan penumpang, sebanyak 7.623.530 penumpang pada tahun 2018. Berdasarkan Perda No. 9 Tahun 2019 Tentang RTRW Tahun 2011 - 2031, Stasiun Sudimara menjadi salah satu stasiun yang ditunjuk untuk dikembangkan menjadi kawasan TOD (Transit Oriented Development). Menjamurnya pengembangan hunian di Kota Tangerang Selatan membuat jarak antara hunian dengan titik simpul transit berjauhan, kendaraan pribadi merupakan salah satu cara menuju titik transit, sehingga menyebabkan kepadatan lalu lintas akibat kapasitas jalan yang kurang memadai dan banyaknya hambatan samping. Tidak terintegrasinya antar moda transportasi yang tersedia memperparah keadaan ini. Oleh sebab itu, akan dilakukan penataan pada area sekitar Stasiun Sudimara dengan memakai konsep TOD. Hal ini dimaksudkan agar tercapainya keharmonisan antara stasiun sebagai titik transit dan kawasan hunian beserta fasilitasnya. Sebelum melakukan hal tersebut, dilakukan terlebih dahulu pencarian potensi serta masalah yang akan ditimbulkan dari rencana tersebut. Metode penelitian yang penulis gunakan adalah kuantitatif dan kualitatif. Penelitian ini akan memberikan hasil berupa rencana induk penataan kawasan dengan konsep TOD.
\end{abstract}

Kata kunci: Hunian; Integrasi; Sudimara; TOD

\begin{abstract}
South Tangerang has become one of the residential choices for commuters. Mayor of the city of South Tangerang said that more than $50 \%$ of its residents work in Special Capital Region of Jakarta. The transportation that commuters use for their daily activities is the KRL Commuter Line. Sudimara Train Station, located in South Tangerang, is the second highest station in the KRL Commuter Line in passenger acquisition, totaling 7.623.530 passengers in 2018. Based on Perda No. 9 of 2019 Concerning Regional Spatial Plans of 2011 - 2031, Sudimara Station is one of the stations designated to be developed into the TOD area. The proliferation of residential developments in South Tangerang makes the distance between the dwelling and transit points far apart, private vehicles are one way to the transit point, causing traffic congestion due to inadequate road capacity and the number of side obstacles. The lack of integration between available modes of transportation exacerbates this situation. Therefore, an arrangement will be made in the area around Sudimara Station by using the TOD concept. This is intended to achieve harmony between the station as a transit point and the residential area and its facilities. Before doing this, will first be done searching for potentials and problems that will arise from the plan. The research method that I use is quantitative and qualitative. This research will provide results in the form of a regional arrangement master plan with the TOD concept.
\end{abstract}

Keywords: Integration; Residential; Sudimara; Transit Oriented Development (TOD) 


\section{PENDAHULUAN}

\section{Latar Belakang}

Kota Tangerang Selatan merupakan salah satu kota yang memiliki pertumbuhan penduduk yang cukup tinggi sebesar 4,16\% dari tahun 2009 hingga 2018. Sebagai salah satu kota penyangga Jakarta, yang merupakan Ibukota dan pusat bisnis Republik Indonesia, Kota Tangerang Selatan menjadi kota yang memiliki daya tarik potensi sebagai tempat hunian bagi para pendatang. Terlebih warga Kota Tangerang Selatan yang bekerja di Jakarta saat ini jumlahnya sudah diatas $50 \%$ (Diany, 2018). Solusi yang disediakan untuk memfasilitasi para pekerja setiap harinya yang tergolong cepat dan murah ialah KRL Commuter Line PT Kereta Commuter Indonesia. Salah satu stasiun yang melayani keberangkatan dan kedatangan KRL Commuter Line adalah Stasiun Sudimara yang terletak di Kel. Jombang, Kec. Ciputat, Kota Tangerang Selatan.

Stasiun Sudimara merupakan stasiun kedua setelah Stasiun Tanah Abang dengan jumlah bangkitan dan tarikan perjalanan tertinggi pada lintas Jalur Rangkasbitung. Jumlah penumpang yang berangkat dan datang dari Stasiun Sudimara pada tahun 2018 mencapai 7.623 .530 orang per tahun atau rata - rata mencapai 20.094 orang per hari pada bulan Oktober 2019 (PT Kereta Commuter Indonesia, 2019). Sebagai kota penyangga ibukota, Kota Tangerang Selatan menjadi hunian bagi para pekerja yang bekerja di Provinsi DKI Jakarta.

Seperti yang telah disebutkan sebelumnya, pertumbuhan penduduk yang cukup tinggi (2009 2018), dengan demikian diperlukannya hunian di masa yang akan datang untuk menampung pertumbuhan penduduk tersebut. Dengan pertumbuhan penduduk yang tinggi dan adanya moda transportasi berbasis rel untuk memudahkan pekerja yang bekerja di Jakarta, TOD merupakan salah satu solusi untuk menyelesaikan keduanya, berdasarkan kajian ITDP, salah dua prinsip dari TOD adalah densify dan mix. Prinsip ini berfungsi agar penduduk mengurangi waktu perjalanan, selain itu sistem densify yang memadatkan hunian menjadi salah satu alternatif dalam penyediaan hunian.

Rencana pembangunan kawasan TOD ini telah tercantum dalam Perda No. 9 Tahun 2019 Tentang Rencana Tata Ruang Wilayah Kota Tangerang Selatan Tahun 2011 - 2031 pada Pasal 25 Ayat 3 Poin $A$, yang berisi pembangunan dan peningkatan stasiun penumpang yang terintegrasi dengan kawasan TOD di Stasiun Sudimara. Usulan ini juga diperkuat dengan adanya berita tentang rencana mengenai penataan kawasan di Stasiun Sudimara terutama mengenai revitalisasi kawasan di sekitar Stasiun Sudimara (Lawi, 2018).

\section{Rumusan Permasalahan}

Rumusan masalah yang terjadi di sekitar Stasiun Sudimara adalah:

a. Kepadatan volume lalu lintas pada sirkulasi menuju Stasiun Sudimara ketika jam sibuk didukung dengan badan jalan yang tidak sesuai standar serta angkot dan ojek daring yang berhenti pada sembarang tempat.

b. Belum terintegrasi antara Stasiun Sudimara dengan fasilitas dan moda transportasi lain disekitarnya.

\section{Tujuan}

Membuat konsep penataan sebagai usulan dan rekomendasi terkait permasalahan di sekitar Stasiun Sudimara dengan cara:

a. Menentukan potensi dan masalah yang terdapat di sekitar Stasiun Sudimara sehingga terjadinya kawasan yang berbasis Transit Oriented Development.

b. Menentukan faktor - faktor yang mempengaruhi bahwa Stasiun Sudimara dapat dikatakan sebagai Transit Oriented Development.

c. Memberikan saran bagaimana untuk mengintegrasikan fasilitas yang mendukung Stasiun Sudimara sehingga terbentuknya kawasan yang berbasis Transit Oriented Development. 


\section{KAJIAN LITERATUR}

\section{Penataan Ruang}

Penataan ruang menurut UU No. 26 Tahun 2007 tentang Penataan Ruang adalah suatu sistem proses perencanaan tata ruang, pemanfaatan ruang, dan pengendalian pemanfaatan ruang. Penyelenggaraan penataan ruang adalah kegiatan yang meliputi pengaturan, pembinaan, pelaksanaan, dan pengawasan penataan ruang.

\section{Superblock}

Superblock merupakan suatu kawasan di konteks urban yang dirancang secara terpadu dan terintegrasi, berdensitas cukup dalam konteks tata guna yang bersifat campuran. (Ridwan Kamil 2008-2009). Dalam desainnya, perencanaan Superblock City mencampurkan beberapa fungsi penggunaan lahan, mulai dari hunian, perkantoran, perbelanjaan, hingga hiburan dalam satu lokasi dan setiap blok bangunan terhubung satu sama lain agar memudahkan orang berjalan kaki.

\section{Transportasi}

Transportasi merupakan pemindahan manusia atau barang dari satu tempat ke tempat lainnya dalam waktu tertentu dengan menggunakan sebuah kendaraan yang digerakkan oleh manusia, hewan, maupun mesin. (Christian, 2013)

\section{Terminal}

Terminal merupakan lokasi bagi para penumpang dan barang masuk dan keluar dari sistem yang merupakan komponen yang sangat penting dalam sistem transportasi. (Morlok, 1988)

\section{Stasiun Kereta Api}

Stasiun kereta api menurut UU No.13 Tahun 1992 Pasal 19 adalah tempat kereta api berangkat dan berhenti untuk melayani naik dan turunnya penumpang dan/atau bongkar muat barang dan/atau untuk keperluan operasi kereta api.

\section{Transit Oriented Development}

Transit Oriented Development (TOD) adalah konsep pengembangan berorientasi transit dengan jenis komunitas pembangunan meliputi campuran dari perumahan, kantor, ritel dan/atau pembangunan komersial lainnya yang terintegrasi dengan lingkungan yang walkable dan terletak setengah mil dari transportasi publik.

\section{Prinsip TOD Menurut ITDP (Institute for Transportation and Development Policy)}

Terdapat delapan prinsip TOD yang dikemukakan oleh ITDP, yaitu:

a. Lingkungan yang mendukung kegiatan berjalan kaki (Walkability).

b. Memprioritaskan jaringan transportasi tidak bermotor (Cycle).

c. Menciptakan pola tata ruang kota yang lebih permeabel terhadap pejalan kaki dan pesepeda (Connect).

d. Mudah mengakses transportasi umum khususnya transportasi berbasis rel atau BRT (Transit).

e. Pencampuran tata guna lahan yang seimbang antar kegiatan (Mix).

f. Mengoptimalkan kepadatan guna mengakomodasi pertumbuhan di area yang terbatas serta berorientasi pada angkutan umum (Densify).

g. Integrasi secara spasial dengan konektivitas berjalan kaki dan dilayani oleh sistem transportasi publik (Compact).

h. Peralihan mobilitas menuju transportasi umum membuat kendaraan pribadi bukan menjadi prioritas (Shift). 


\section{METODE}

Pengumpulan data yang dilakukan dengan metode - metode bertujuan untuk mengumpulkan data yang diperlukan sesuai dengan kebutuhan studi yang dilakukan. Metode pengumpulan data ini dibedakan menjadi dua jenis, yaitu data primer dan data sekunder. Berikut uraian pada masing - masing teknik pengumpulan data:

a. Data Primer

Data primer dilakukan oleh penulis sendiri dengan cara mengunjungi atau menghubungi langsung kepada orang / badan / instansi / perusahaan yang bersangkutan terkait data yang dibutuhkan dalam penulisan Tugas Akhir ini. Pengumpulan data primer yang dilakukan penulis terdiri dari beberapa metode, diantaranya adalah:

1. Survei Lapangan

Survei lapangan diantaranya untuk mengetahui:
a.) Batas - batas lahan.
b.) Aksesibilitas lahan.
c.) Proximity lahan.
d.) Karakteristik lahan.
e.) Kondisi visual lahan.

2. Dokumentasi

Dokumentasi mencakup:
a.) Foto kondisi eksisting.
b.) Foto objek bangunan yang tidak dapat direlokasi.
c.) Foto batas - batas lahan.
d.) Foto fisik masalah.
e.) Foto lingkungan sekitar area penataan.

b. Data Sekunder

Data sekunder dilakukan penulis dengan mencari informasi terkait yang dibutuhkan dalam penulisan Tugas Akhir. Data sekunder diperoleh secara tidak langsung, dengan kata lain, data tersebut diperoleh melalui instansi, media cetak dan elektronik yang terkait dengan objek studi.

1. Instansi Terkait

Instansi terkait yang dimaksud adalah instansi pemerintah dan perusahaan operator KRL yang merupakan instansi yang memiliki data terkait keperluan studi ini. Bentuk keperluan data yang diinginkan mencakup:

a.) Data kependudukan dari BPS Kota Tangerang Selatan.

b.) Kebijakan dan peraturan daerah tertentu dari Pemerintah Kota Tangerang Selatan.

c.) Harga lahan dan status hak kepemilikan lahan dari Kantor Pertanahan Kota Tangerang Selatan.

d.) Arahan dan regulasi dari Bappeda Kota Tangerang Selatan.

e.) Rencana pengembangan transportasi umum dari Dinas Perhubungan Kota Tangerang Selatan.

f.) Data pengguna KRL di Stasiun Sudimara dari PT Kereta Commuter Indonesia.

2. Media Elektronik

Media elektronik yang digunakan untuk memperoleh informasi tambahan sebagai acuan dan juga dalam melakukan analisa dalam melakukan pengembangan di sekitar kawasan TOD Stasiun Sudimara. Informasi tersebut dapat berupa:

a.) Teori - teori yang mendukung Penulisan.

b.) Citra satelit terhadap lokasi Penulisan.

c.) Surat kabar daring yang memuat berita - berita atau informasi lain yang berguna dalam kegiatan Penulisan ini. 


\section{DISKUSI DAN HASIL}

Kota Tangerang Selatan merupakan salah satu kota yang terdapat di Provinsi Banten, berdasarkan luas wilayahnya, Kota Tangerang Selatan memiliki wilayah seluas $147,19 \mathrm{~km}^{2}$ atau sebesar 1,52\% dari luas total wilayah Provinsi Banten. Kota Tangerang Selatan terdiri dari tujuh kecamatan dan 54 kelurahan. Lokasi objek studi berada pada dua kecamatan dan dua kelurahan yang berbeda, yaitu Kelurahan Jombang di Kecamatan Ciputat dan Kelurahan Pondok Pucung di Kecamatan Pondok Aren dengan luas penataan sebesar 59,4 Ha.Berdasarkan Peraturan Presiden Republik Indonesia No. 55 Tahun 2018 Tentang Rencana Induk Transportasi Jakarta, Bogor, Depok, Tangerang dan Bekasi Tahun 2018 - 2029 serta Peraturan Daerah Kota Tangerang Selatan No. 9 Tahun 2019 Tentang Rencana Tata Ruang Wilayah Tahun 2011 - 2031, Stasiun Sudimara tercantum sebagai rencana pengembangan kawasan berbasis TOD dengan skala sub kota.

Objek studi terletak berdekatan dengan kawasan pengembangan besar Bintaro Jaya, oleh sebab itu terdapat beberapa pusat kegiatan terdekat, diantaranya adalah CBD Bintaro Jaya, Kawasan Pendidikan Universitas Pembangunan Jaya dan RS Ichsan Medical Centre. Adanya kawasan pengembangan tersebut, cukup mudah dicapai menuju area objek studi, diantaranya dapat melalui Jalan Tol Jakarta - Serpong yang menghubungkan area objek studi dengan Jabodetabek, Jalan Jombang Raya yang menghubungkan Kota Tangerang Selatan dengan Kota Tangerang. Selain menggunakan kendaraan pribadi, area objek studi juga dilayani oleh beberapa moda transportasi umum, yaitu: KRL Commuter Line, Angkot C.02, Angkot D.06 dan Angkot D.08.

Berdasarkan data yang telah dihimpun dari BPS Kota Tangerang Selatan lalu disesuaikan dengan delineasi area, kepadatan penduduk pada delineasi area terbilang rendah (SNI 03-1733-2004), yakni berkisar 152 jiwa/Ha atau sebanyak 9.016 jiwa dalam 59,4 Ha.

Jumlah penumpang KRL Commuter Line yang naik dan turun di Stasiun Sudimara pada tahun 2018 sebanyak 7.623.530 penumpang, dengan pertumbuhan pencapaian penumpang naik sebesar $13,11 \%$ dari tahun 2015 . Berdasarkan perolehan jumlah penumpang tersebut, Stasiun Sudimara mendapati urutan kedua setelah Stasiun Tanah Abang.

Karakteristik wilayah yang berada di sekitar tapak didominasi oleh hunian horizontal. Karakteristik sebelah utara didominasi oleh sektor pelayanan sosial dan umum, seperti SDN 4 Jombang, Puskesmas Jombang, SMPN 1 Terbuka Diponegoro, Sekolah PKBM Maleo dan Pasar Jombang. Sementara sebelah selatan didominasi oleh fasilitas penyedia parkir (park and ride) untuk menunjang aktivitas mobilitas di Stasiun Sudimara dan didominasi oleh pemukiman tidak tertata. Berdekatan dengan lokasi tapak terdapat Rest Area Tol Jakarta - Serpong km 7+200 yang hanya dapat diakses menggunakan jalan tol.

Tabel 1. Luas Penggunaan Lahan di sekitar Stasiun Sudimara

\begin{tabular}{|c|c|c|c|}
\hline No. & Status Lahan & Luas (Ha) & Persentase \\
\hline 1. & Campuran & 2,73 & $4,71 \%$ \\
\hline 2. & Hunian & 30,77 & $51,80 \%$ \\
\hline 3. & Industri & 0,85 & $1,45 \%$ \\
\hline 4. & Jalur Hijau & 3,07 & $5,18 \%$ \\
\hline 5. & Perdagangan dan Jasa & 4,29 & $7,22 \%$ \\
\hline 7. & Lahan Kosong & 5,61 & $9,45 \%$ \\
\hline 8. & Pelayanan Sosial dan Umum & 6,00 & $10,10 \%$ \\
\hline 9. & Pemerintahan Daerah & 0,13 & $0,23 \%$ \\
\hline 10. & Ruang Terbuka Biru & 0,43 & $0,74 \%$ \\
\hline 11. & Jalan & 5,41 & $9,12 \%$ \\
\hline & Total & 59,40 & $100 \%$ \\
\hline
\end{tabular}

Sumber: Hasil Analisa Penulis, 2020 
Status penggunaan lahan pada objek studi didominasi oleh status lahan yang tidak / belum terdaftar dengan luas 24,76 ha atau sebesar $41,58 \%$, sementara untuk hak milik dengan luas 18,18 ha atau sebesar $30,64 \%$, hak pakai memiliki luas 11,60 ha atau sebesar $19,53 \%$, hak pengelolaan memiliki luas 2,48 ha atau sebesar $4,21 \%$ dan status lahan terkecil adalah HGB dengan luas 2,36 ha atau sebesar $4,04 \%$ dari total keseluruhan lahan menurut Kementerian ATR/BPN.

Tabel 2. Luas Status Lahan di sekitar Stasiun Sudimara

\begin{tabular}{clcc}
\hline No. & \multicolumn{1}{c}{ Status Lahan } & Luas $(\mathrm{Ha})$ & Persentase \\
\hline 1. & Hak Milik & 18,18 & $30,64 \%$ \\
\hline 2. & Hak Guna Bangunan & 2,36 & $4,04 \%$ \\
\hline 3. & Hak Pakai & 11,60 & $19,53 \%$ \\
\hline 4. & Hak Pengelolaan & 2,48 & $4,21 \%$ \\
\hline 5. & Belum Terdaftar & $\mathbf{2 4 , 7 6}$ & $41,58 \%$ \\
\hline & Total & $\mathbf{5 9 , 4 0}$ & $\mathbf{1 0 0 \%}$ \\
\hline
\end{tabular}

Sumber: Kementerian ATR/BPN Republik Indonesia, 2020

\section{Kebutuhan Ruang}

a. Rencana Kependudukan

Rencana kependudukan berguna untuk mengetahui daya tampung kawasan serta proyeksi pertumbuhan penduduk di dalam delineasi area. Rencana kependudukan ini terdiri dari:

1. Penduduk Rencana

Penduduk rencana didapatkan berdasarkan jumlah penduduk dalam delineasi area yang diproyeksikan secara rentetan dalam sembilan tahun terakhir. Pertumbuhan penduduk rata - rata Kelurahan Jombang setiap tahunnya sebesar 3,8\% dan di Kelurahan Pondok Pucung sebesar $3,7 \%$.

Tabel 3. Proyeksi Penduduk dalam Delineasi Area

\begin{tabular}{|c|c|c|c|c|c|c|c|c|c|}
\hline \multirow[b]{2}{*}{ No. } & \multirow[b]{2}{*}{ Kelurahan } & \multicolumn{3}{|c|}{ Penduduk (Jiwa) } & \multirow[b]{2}{*}{$\begin{array}{l}\text { Luas } \\
\left(\mathrm{km}^{2}\right)\end{array}$} & \multirow[b]{2}{*}{$\begin{array}{l}\text { Kepadatan } \\
\text { (Jiwa/km²) }\end{array}$} & \multirow{2}{*}{$\begin{array}{l}\text { Asumsi } \\
\text { Jumlah } \\
\text { Penduduk } \\
\text { (Jiwa) }\end{array}$} & \multirow{2}{*}{$\begin{array}{c}\text { Luas } \\
\text { Delineasi } \\
\text { Area } \\
\left(\mathrm{km}^{2}\right)\end{array}$} & \multirow{2}{*}{$\begin{array}{l}\text { Asumsi } \\
\text { Kepadatan } \\
\text { Penduduk } \\
(\text { Jiwa/km²) }\end{array}$} \\
\hline & & $\begin{array}{l}\text { Laki - } \\
\text { laki }\end{array}$ & Perempuan & Total & & & & & \\
\hline 1. & Jombang & 26.771 & 25.861 & 52.632 & 3,45 & 15.256 & 8.901 & 0,583 & 5.193 \\
\hline 2. & $\begin{array}{l}\text { Pondok } \\
\text { Pucung }\end{array}$ & 19.265 & 20.596 & 39.861 & 3,59 & 11.104 & 116 & 0,010 & 2 \\
\hline
\end{tabular}

Sumber: Hasil Analisa Penulis, 2020

Jumlah penduduk dalam delineasi area didapatkan dari jumlah penduduk dalam satu kelurahan dikalikan dengan persentase luas wilayah kelurahan yang terdapat di dalam delineasi area, sehingga didapatkan jumlah penduduk delineasi area yang terdapat Kelurahan Jombang sebanyak 8.901 jiwa dan di Kelurahan Pondok Pucung sebanyak 116 jiwa.

Tabel 4. Proyeksi Penduduk dalam Delineasi Area

\begin{tabular}{cccc} 
No. & Tahun & Kelurahan Jombang & Kelurahan Pondok Pucung \\
\hline 1. & 2018 & 8.901 & 116 \\
\hline 2. & 2020 & 9.595 & 125 \\
\hline 3. & 2025 & 11.575 & 150 \\
\hline 4. & 2030 & 13.963 & 180 \\
\hline 5. & 2031 & 14.497 & 187 \\
\hline
\end{tabular}

Sumber: Hasil Analisa Penulis, 2020 
Perhitungan proyeksi dilakukan hingga tahun 2031, hal ini berdasarkan waktu pelaksanaan yang tercantum pada Peraturan Daerah RTRW Kota Tangerang Selatan yang memiliki waktu pelaksanaan hingga empat tahap, yaitu: Tahap pertama (2011 - 2016), Tahap kedua (2017 - 2021), Tahap ketiga (2022 - 2026) dan Tahap keempat (2026 2031). Demikian jumlah proyeksi penduduk pada tahun 2031 dalam delineasi area sebanyak 14.684 jiwa.

2. Penduduk Relokasi

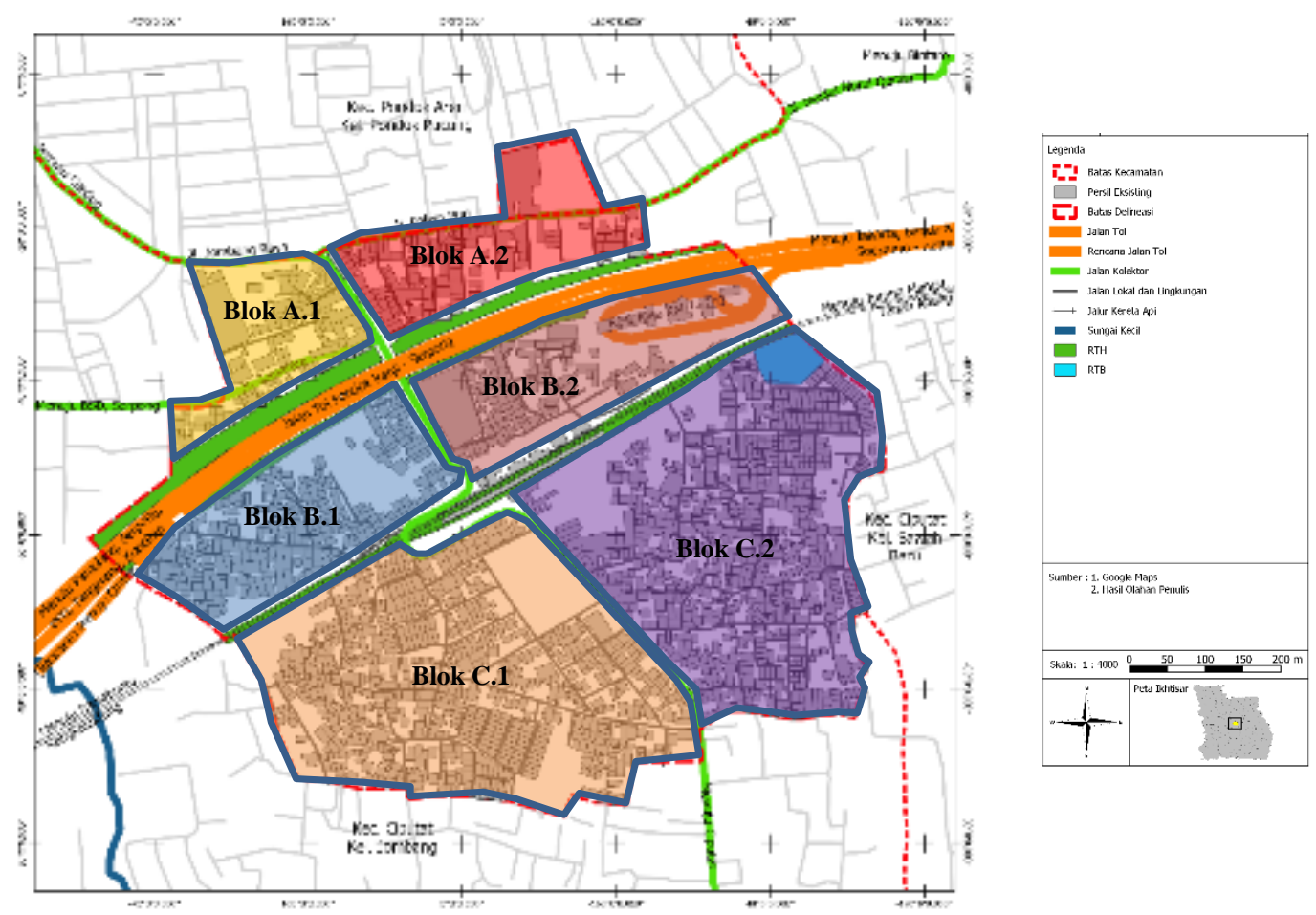

Gambar 1. Blok Penduduk Relokasi Sumber: Hasil Analisa Penulis, 2020

Tabel 5. Jumlah Rumah Relokasi Berdasarkan Blok

\begin{tabular}{|c|c|c|}
\hline No. & Blok & Rumah Relokasi \\
\hline 1. & A.1 & 118 Unit \\
\hline 2. & A. 2 & 110 Unit \\
\hline 3. & B.1 & 324 Unit \\
\hline 4. & B. 2 & 102 Unit \\
\hline 5. & $\begin{array}{ll} \\
C .1\end{array}$ & 780 Unit \\
\hline 6. & C.2 & 820 Unit \\
\hline \multicolumn{2}{|c|}{ Total } & 2.254 Unit \\
\hline
\end{tabular}

Sumber: Hasil Analisa Penulis, 2020

Berdasarkan tabel di atas, dapat diasumsikan jumlah unit yang terkena relokasi adalah sebanyak 2.254 unit bangunan. Apabila diasumsikan 1 unit bangunan adalah $1 \mathrm{KK}$, maka jumlah penduduk yang terkena relokasi sebanyak 9.016 jiwa.

3. Penduduk Migrasi

Merebaknya pandemi Covid-19 di Indonesia mengakibatkan kantor - kantor pemerintahan daerah Kota Tangerang Selatan, sehingga membuat penulis kesulitan mendapatkan data migrasi penduduk. Oleh sebab itu, penulis mengganti data kependudukan migrasi dengan data jumlah dan pertumbuhan unit rumah tapak baru 
dalam radius $3 \mathrm{~km}$ mulai dari tahun 2005 hingga tahun 2016, sehingga didapatkan data sebagai berikut:

Tabel 6. Pertumbuhan Unit Rumah Baru

\begin{tabular}{|c|c|c|c|c|c|}
\hline \multirow{2}{*}{ No. } & \multirow{2}{*}{ Tahun } & \multicolumn{2}{|c|}{ Pertumbuhan Perumahan } & \multicolumn{2}{|c|}{ Rata - rata Pertumbuhan } \\
\hline & & (Unit) & $(\%)$ & (Unit) & (\%) \\
\hline 1. & 2005 & 1.267 & $54 \%$ & \multirow{12}{*}{567} & \multirow{12}{*}{$54 \%$} \\
\hline 2. & 2006 & 1.954 & $-80 \%$ & & \\
\hline 3. & 2007 & 397 & $237 \%$ & & \\
\hline 4. & 2008 & 1.338 & $-81 \%$ & & \\
\hline 5. & 2009 & 251 & $129 \%$ & & \\
\hline 6. & 2010 & 575 & $-54 \%$ & & \\
\hline 7. & 2011 & 264 & $3 \%$ & & \\
\hline 8. & 2012 & 272 & $-32 \%$ & & \\
\hline 9. & 2013 & 184 & $-65 \%$ & & \\
\hline 10. & 2014 & 65 & $-52 \%$ & & \\
\hline 11. & 2015 & 31 & $535 \%$ & & \\
\hline 12. & 2016 & 197 & $54 \%$ & & \\
\hline Tot & & & - & - & - \\
\hline
\end{tabular}

Sumber: Hasil Analisa Penulis, 2020

Berdasarkan tabel di atas, didapatkan bahwa pertumbuhan unit perumahan setiap tahunnya sebesar $54 \%$ atau bertambah 567 unit/tahun. Total unit perumahan yang terbangun dari tahun 2005 hingga 2016 sebanyak 6.795 unit. Demikian, dapat diasumsikan jika dalam satu unit terdapat 4 anggota keluarga, maka penduduk migrasi diketahui sebanyak 27.180 jiwa.

Setelah diketahui jumlah proyeksi penduduk sebanyak 14.684 jiwa, jumlah penduduk yang terkena relokasi sebanyak 9.016 jiwa dan penduduk migrasi sebanyak 27.180 jiwa, kemudian dapat disimpulkan bahwa rencana kependudukan dalam delineasi area berjumlah $\mathbf{5 0 . 8 8 0}$ jiwa.

b. Program Ruang

Berdasarkan perhitungan program ruang pada tabel 7 di bawah ini, lahan yang digunakan adalah seluas $41,35 \mathrm{Ha}$ dari 59,40 Ha yang tersedia atau sebesar $69,60 \%$ lahan potensial untuk dilakukan penataan, lahan ini adalah lahan neto (luas bersih) diluar bangunan atau area yang tidak dapat dibebaskan serta rencana jaringan jalan berdasarkan rencana dari Pemerintah Provinsi Banten melalui Dinas Bina Marga dan Tata Ruang berupa underpass serta rencana jaringan jalan lainnya. 
Tabel 7. Perhitungan Program Ruang

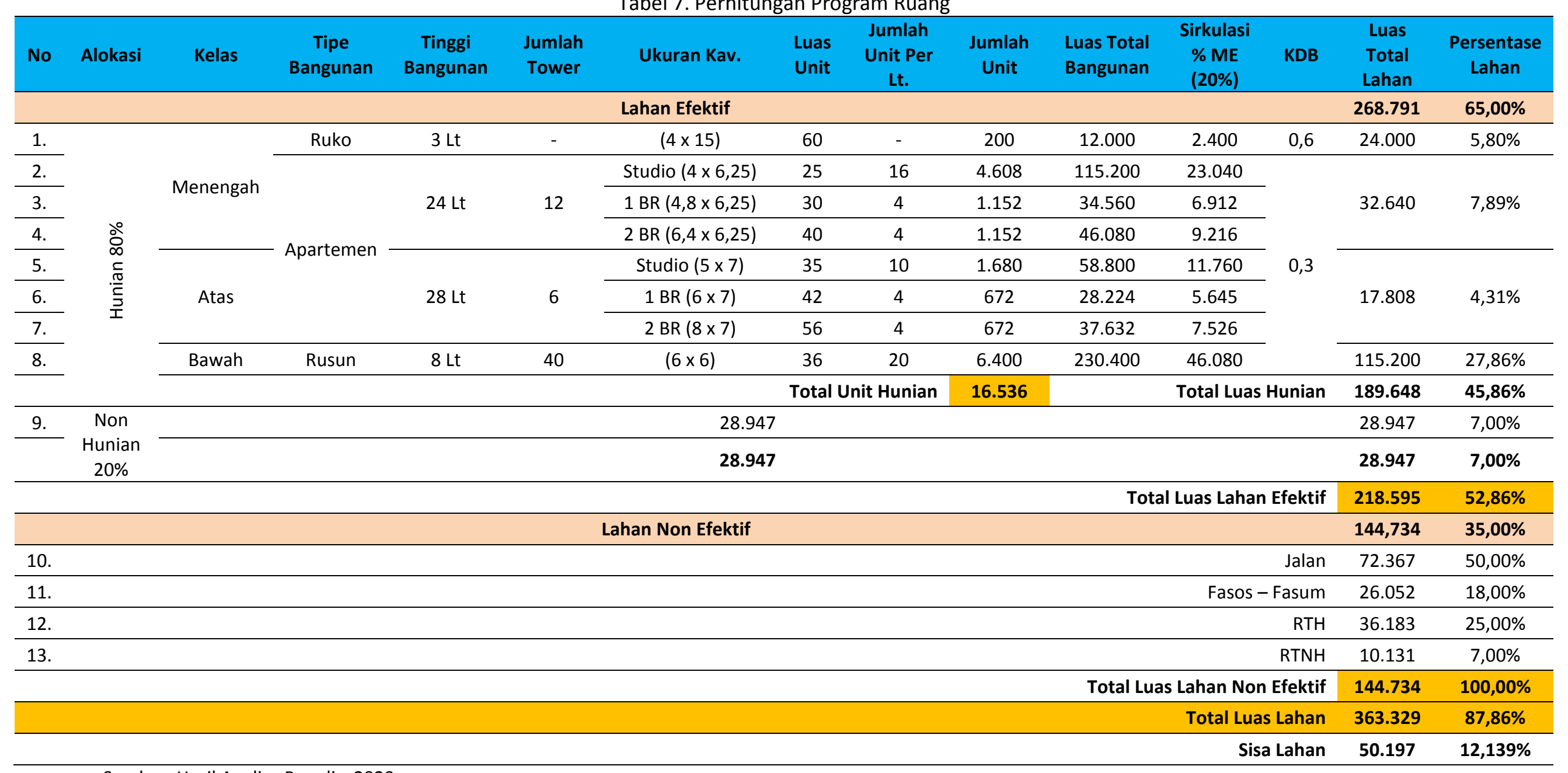


Hingga saat ini, data mengenai pembangunan hunian vertikal TOD di dalam Stasiun Sudimara belum penulis dapatkan, sehingga dengan adanya pembangunan hunian vertikal, maka jumlah unit akan bertambah. Dengan asumsi lahan eksisting Stasiun Sudimara, maka dapat dibangun sebanyak 6 menara apartemen. Sama seperti perhitungan jumlah unit untuk apartemen kelas atas, jumlah unit yang tersedia dari 6 menara apartemen di dalam area Stasiun Sudimara sebanyak 3.024 unit dengan uraian untuk tipe studio sebanyak 1.680 unit, tipe one bed room sebanyak 672 unit dan tipe two bed room sebanyak 672 unit. Demikian, jumlah unit yang tersedia berdasarkan perhitungan program ruang (16.536 unit) dan penambahan dari bangunan TOD Stasiun Sudimara (1.680 unit) adalah sebanyak 19.560 unit.

\section{Rencana Penataan}

Rencana penataan dilakukan mengikuti arahan zonasi yang telah tercantum dalam Peraturan Daerah Kota Tangerang Selatan No. 9 Tahun 2019 Tentang Rencana Tata Ruang Wilayah Tahun 2011 - 2031. Peruntukan beserta intensitas lahan diarahkan menjadi sebagai berikut:

Tabel 7. Jumlah Rumah Relokasi Berdasarkan Blok

\begin{tabular}{clccc}
\hline No. & \multicolumn{1}{c}{ Peruntukan } & KDB Maks & KLB Maks & KB Maks \\
\hline 1. & RTH Lapangan & $25 \%$ & 1,2 & 1 Lantai \\
\hline 2. & Perumahan Vertikal & $60 \%$ & 3 & - \\
\hline 3. & Rumah Susun & $60 \%$ & 3 & 10 Lantai \\
\hline 4. & Perdagangan dan Jasa & $60 \%$ & 9,6 & - \\
\hline 5. & RTNH & $10 \%$ & 0,4 & 2 Lantai \\
\hline
\end{tabular}

Sumber: Perda RTRW Kota Tangerang Selatan No. 9 Tahun 2019, 2019

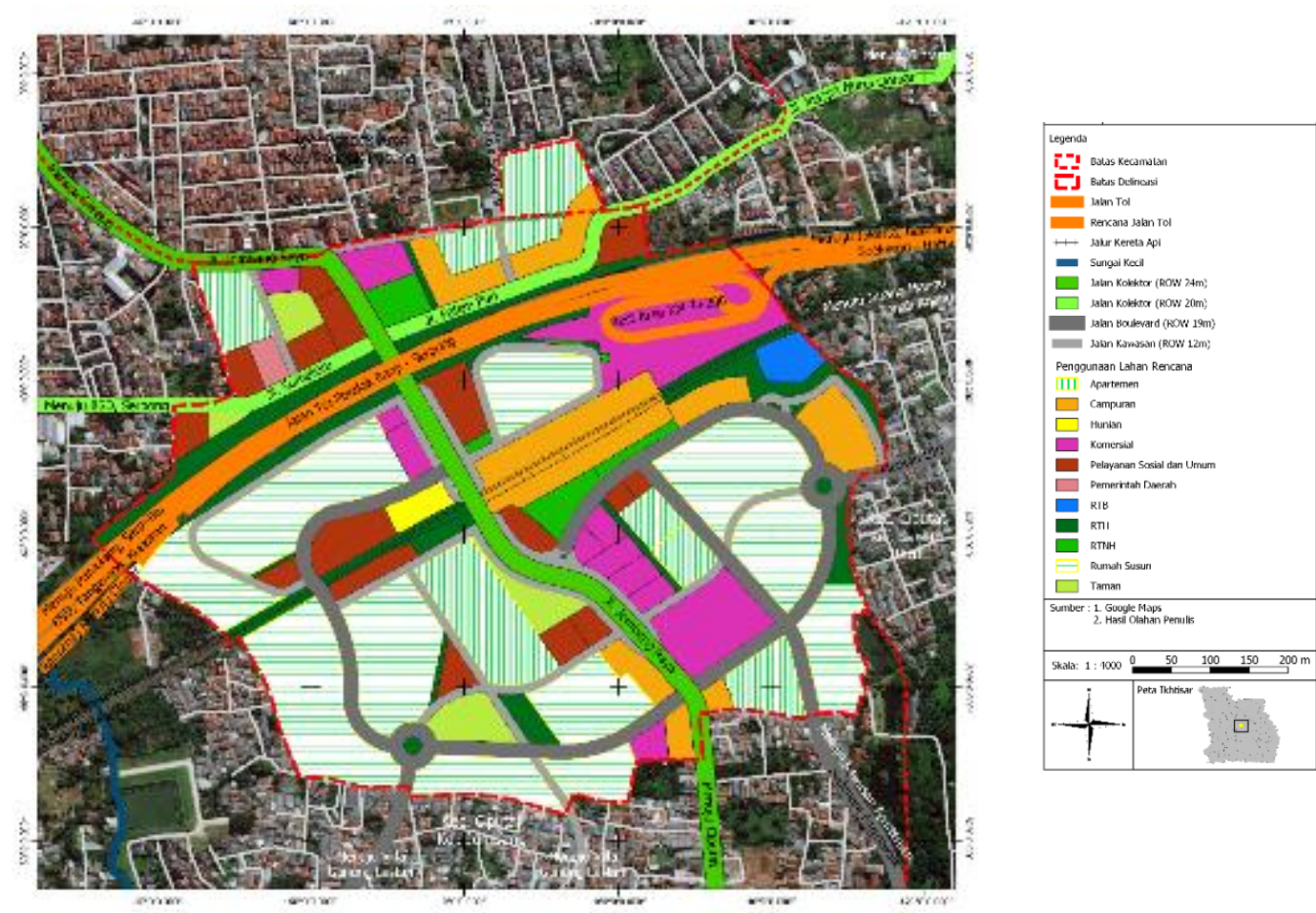

Gambar 2. Rencana Induk Penataan Kawasan Sekitar TOD Stasiun Sudimara Sumber: Hasil Analisa Penulis, 2020

Berdasarkan gambar Rencana Induk Penataan Kawasan Sekitar TOD Stasiun Sudimara, berikut gambaran perencanaan berupa gambar 3D pada masing - masing blok. 


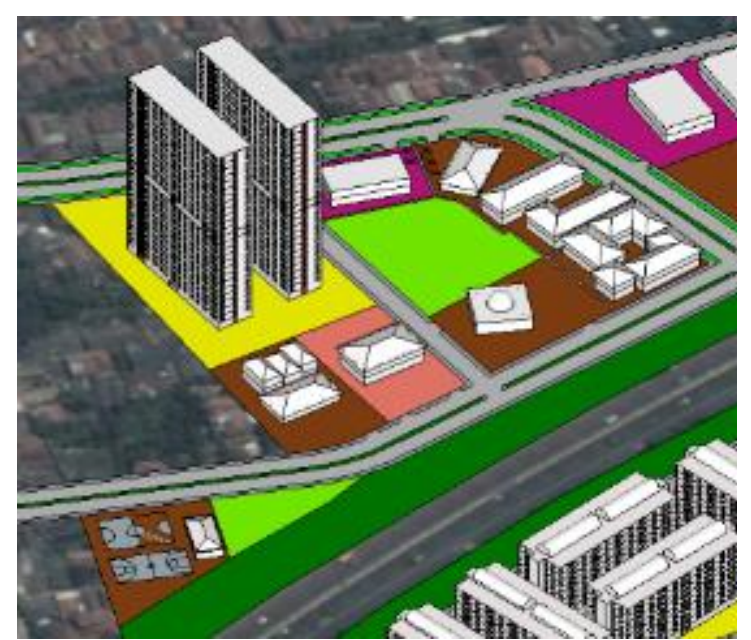

Gambar 3. Rencana Induk Blok A.1 Sumber: Hasil Analisa Penulis, 2020

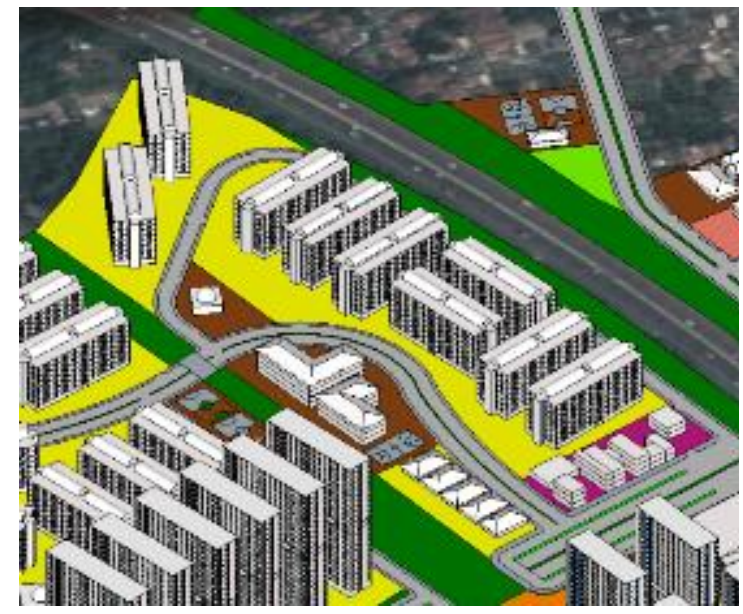

Gambar 5. Rencana Induk Blok B.1

Sumber: Hasil Analisa Penulis, 2020

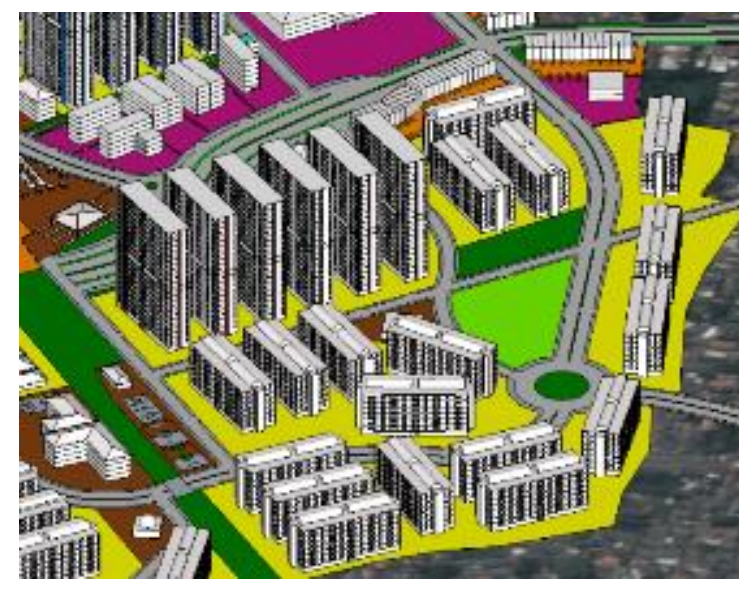

Gambar 7. Rencana Induk Blok C.1

Sumber: Hasil Analisa Penulis, 2020

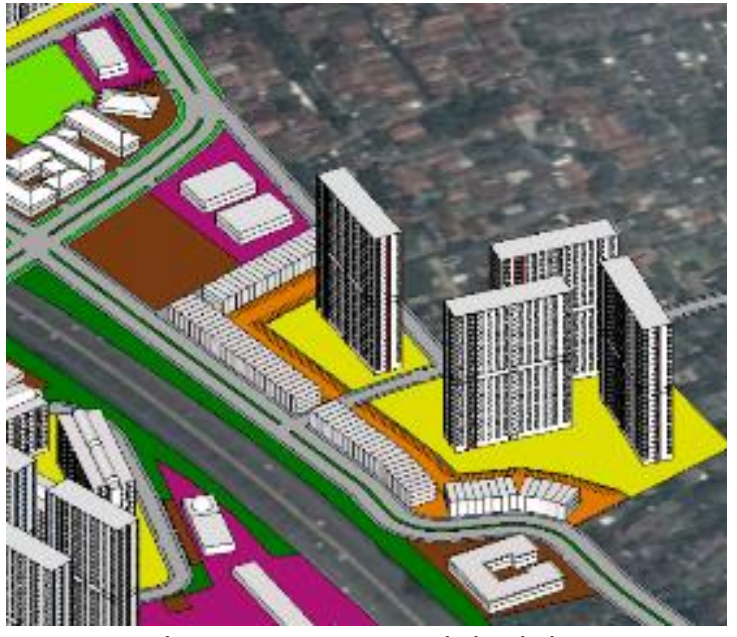

Gambar 4. Rencana Induk Blok A.2

Sumber: Hasil Analisa Penulis, 2020

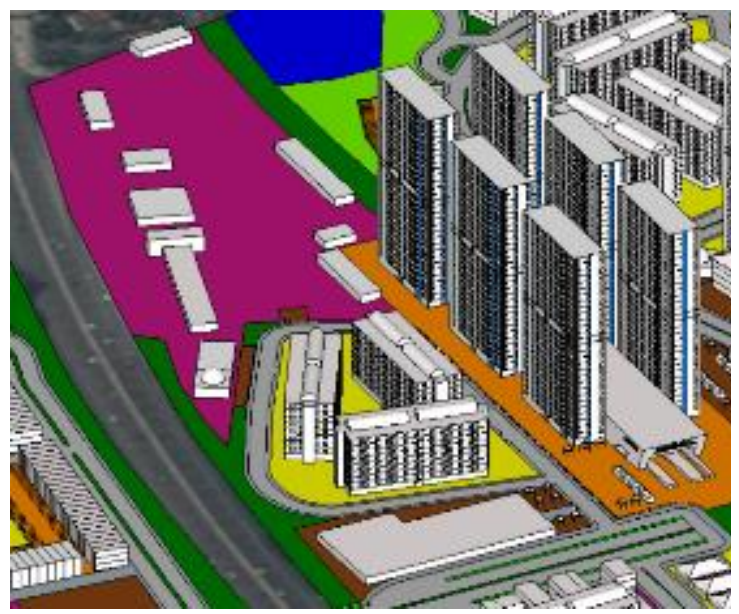

Gambar 6. Rencana Induk Blok B.2

Sumber: Hasil Analisa Penulis, 2020

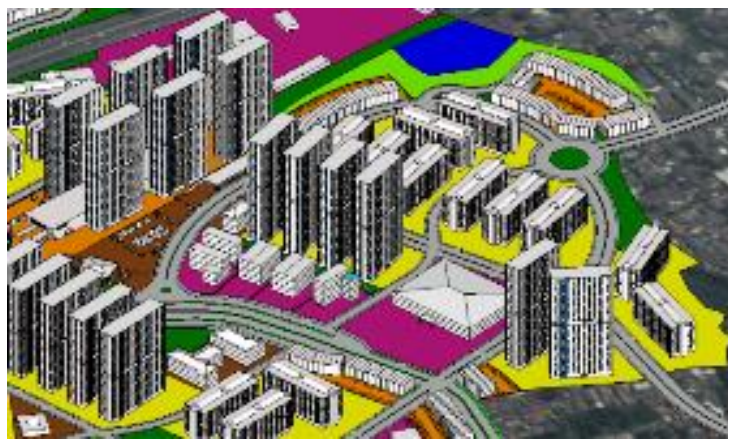

Gambar 8. Rencana Induk Blok C.2

Sumber: Hasil Analisa Penulis, 2020 


\section{KESIMPULAN DAN SARAN Kesimpulan}

Berdasarkan Peraturan Presiden Republik Indonesia No. 55 Tahun 2018 Tentang Rencana Induk Transportasi Jakarta, Bogor, Depok, Tangerang dan Bekasi Tahun 2018 - 2029 dan Peraturan Daerah Kota Tangerang Selatan No. 9 Tahun 2019 Tentang Rencana Tata Ruang Wilayah Tahun 2011 - 2031, telah tercantum bahwa Stasiun Sudimara merupakan salah satu stasiun di Kota Tangerang Selatan yang ditunjuk untuk dijadikan sebagai kawasan pengembangan TOD dengan skala Sub Kota. Berdasarkan Peraturan Menteri Agraria dan Tata Ruang/BPN No. 16 Tahun 2017 Tentang Pedoman Pengembangan Kawasan Berorientasi Transit, radius pencapaian yang dibutuhkan pada TOD skala Sub Kota sebesar 400m.

Meskipun objek studi berdekatan dengan kawasan pengembangan Bintaro Jaya $( \pm 1,4 \mathrm{~km})$, namun sekitar objek studi belum terdapat intervensi investor, hal ini membuat perkembangan kawasan sekitar Stasiun Sudimara tidak berkembang, padatnya permukiman penduduk, jarang ditemukannya lahan kosong, serta karakteristik demografi masyarakat merupakan beberapa penyebab dari tidak adanya investor yang masuk pada kawasan ini.

Seperti yang telah dijelaskan sebelumnya, objek studi berdekatan dengan kawasan pengembangan Bintaro Jaya, oleh karena itu penulis menempatkan area objek studi sebagai area penunjang dengan penyediaan hunian terjangkau yang mengoptimalkan kepadatan dengan menyesuaikan intensitas pembangunan bagi seluruh lapisan masyarakat. Selain sebagai penunjang dari Bintaro Jaya, penataan kawasan sekitar Stasiun Sudimara juga dijadikan area penunjang bagi pembangunan TOD Stasiun Sudimara yang dilakukan oleh salah satu perusahaan BUMN karya.

Pembangunan hunian yang dilakukan berdekatan dengan stasiun beserta fasilitas - fasilitas lainnya seperti komersial, pelayanan umum \& sosial serta rekreasi membuat aktivitas dalam kawasan menjadi hidup dan dapat mudah ditempuh baik hanya dengan berjalan kaki maupun menggunakan sepeda serta mendorong untuk menggunakan angkutan umum lainya yang tersedia, sehingga mengurangi penggunaan kendaraan bermotor yang berakibat berkurangnya emisi gas karbon. Demikian, hal ini merupakan suatu manfaat dari adanya konsep TOD serta cocok bagi para pekerja dari segala tingkat pendapatan yang tinggal pada area sub-urban yang bekerja pada daerah urban.

Penataan kawasan sekitar Stasiun Sudimara dilakukan bertahap dalam dua tahap. Pada tahap pertama dilakukan berdasarkan perhitungan jumlah proyeksi penduduk sampai tahun 2031 (Batas akhir Perda RTRW Kota Tangerang Selatan), sementara pada tahap pertama dilakukan berdasarkan sisa lahan yang tersedia yang dapat dilakukan selama 5 tahun dari tahun 2032 hingga tahun 2037.

\section{Saran}

Terdapat beberapa saran pada objek studi mengenai kawasan TOD di Stasiun Sudimara, yaitu:

a. Terdapat rencana pembangunan underpass pada perlintasan sebidang antara Stasiun Sudimara dengan Jalan Jombang Raya yang dilakukan oleh Dinas Bina Marga dan Tata Ruang Provinsi Banten, namun hingga saat ini belum ada titik terang pembangunan underpass tersebut akan segera dibangun.

b. Adanya pembatasan ketinggian bangunan pada rumah susun (maksimal 10 lantai) mengakibatkan tidak optimalnya dalam memanfaatkan lahan yang ada. Sementara, kawasan ini merupakan area yang direncanakan sebagai area TOD.

c. Pemerintah Kota Tangerang Selatan harus membuat badan atau divisi khusus untuk menangani kawasan TOD ini, mulai dari perencanaan, pembangunan hingga pengelolaan. 
Hal ini dimaksudkan sebagai salah satu bentuk partisipasi pemerintah daerah untuk memajukan area yang belum terkena intervensi dari investor.

d. Area ini merupakan area yang telah terbangun padat penduduk, oleh sebab itu ketika akan dimulai penataan, harus melibatkan masyarakat setempat dengan pendekatan perencanaan partisipatif dan padat karya, serta bagi warga yang rumahnya terkena pembangunan, maka warga tersebut berhak untuk mendapatkan satu unit hunian yang akan disediakan.

\section{REFERENSI}

Chairi, M., Yossyafra, \& Putri, E. (2017). Perencanaan Integrasi Layanan Operasional Antar Moda Railbus dan Angkutan Umum di Kota Padang. 2-3.

Deliyanto, B. (2014). Pengenalan Lahan. Tangerang Selatan: Universitas Terbuka.

Diany, A. R. (2018, May 7). Pemkot Tangsel Revitalisasi Lahan Sekitar Stasiun Jadi TOD. (G. F. Lawi, Pewawancara)

Fani. (2019, November). Transit - Oriented Development (TOD). Diambil kembali dari Institute for Transportation and Development Policy: http://www.itdpindonesia.org/tod/transit-oriented-development-tod/

Institute for Transportation and Development Policy. (2017). TOD Standard 3.0. New York, New York, United States of America.

Kamil, M. R. (2008, September 27). Diambil kembali dari https://ridwankamil.wordpress.com/2008/09/27/superblok-sebagai-model-kendalipembangunan-kota/

Kementerian Pekerjaan Umum dan Perumahan Rakyat. (1997). Kamus Istilah Pengembangan Wilayah. Jakarta: Kementerian Pekerjaan Umum dan Perumahan Rakyat.

Kementerian Pekerjaan Umum dan Perumahan Rakyat. (2016). Kamus Istilah Pengembangan Wilayah. Jakarta: Kementerian Pekerjaan Umum dan Perumahan Rakyat.

Lawi, G. F. (2018, Mei 7). Bisnis.com. Retrieved from Bisnis.com: https://ekonomi.bisnis.com/read/20180507/49/792512/pemkot-tangsel-revitalisasilahan-sekitar-stasiun-jadi-tod

Perquin, B. (1921). Nederlandsch Indische staatsspoor- en tramwegen. Amsterdam: Bureau Industria.

PT Kereta Commuter Indonesia. (2019, November 11). Volume Pengguna KRL Tahun 2018. Kota Administrasi Jakarta Pusat, DKI Jakarta, Indonesia.

Republik Indonesia. (2008). Peraturan Presiden Republik Indonesia No. 54 Tahun 2008 Tentang Penataan Ruang Kawasan Jakarta, Bogor, Depok, Tangerang, Bekasi, Puncak dan Cianjur. Jakarta: Kementerian Sekretariat Negara.

Suwardjoko, W. P. (2001). Pengelolaan Lalu Lintas dan Angkutan Jalan. Bandung: Institut Teknologi Bandung.

Tangerang Selatan. (2019). Peraturan Daerah Kota Tangerang Selatan No. 9 Tahun 2019 Tentang Perubahan Atas Peraturan Daerah No. 15 Tahun 2011 Tentang Rencana Tata Ruang Wilayah Kota Tangerang Selatan Tahun 2011 - 2031. Kota Tangerang Selatan: Sekretaris Daerah Kota Tangerang Selatan.

Urban Hub. (t.thn.). Urban Hub. Diambil kembali dari Urban Hub: https://www.urbanhub.com/buildings/mixed-use-buildings-for-diversified-sustainable-sites/ 
